\title{
Retraction Note to: Surface Reaction and Transport in Oxides Formed on FeCrAl Alloys in High Temperature Nitridation Environments
}

Christine Geers, Vedad Babic, Lars-Gunnar Johansson and Itai Panas

\section{Retraction Note to:}

Chapter 36 in: The Minerals, Metals \& Materials Society (ed.), TMS 2017 146th Annual Meeting \& Exhibition Supplemental Proceedings, The Minerals, Metals \& Materials Series, DOI 10.1007/978-3-319-51493-2_36

The Minerals, Metals \& Materials Society, editor of the publication TMS 2017 146th Annual Meeting \& Exhibition Supplemental Proceedings, is retracting the book chapter, "Surface Reaction and Transport in Oxides Formed on FeCrAl Alloys in High Temperature Nitridation Environments" (DOI 10.1007/978-3-31951493-2_36). The corresponding author requested this retraction because an image was used for which the authors do not hold copyright. The authors could not obtain permission to use the image.

The retracted online version of this chapter can be found at http://dx.doi.org/10.1007/978-3-319-51493-2_36 